Yasuyuki Suzuki • Zhongyi Zhang • Nobuyuki Shimozawa

Masami Muro • Hideaki Shono • Shuji Toda

Shin-ichi Miyahara • Takashi Hashimoto • Nobuteru Usuda

Masayuki Ito · Sachio Takashima • Naomi Kondo

\title{
Prenatal diagnosis of peroxisomal D-3-hydroxyacyl-CoA dehydratase / D-3- hydroxyacyl-CoA dehydrogenase bifunctional protein deficiency
}

Received: October 22, 1998 / Accepted: December 5, 1998

\begin{abstract}
The prenatal diagnosis of peroxisomal D-3hydroxyacyl-coenzyme A (CoA) dehydratase/ D-3-hydroxyacyl-CoA dehydrogenase bifunctional protein (D-BP) deficiency was performed by peroxisomal $\beta$-oxidation assay, indirect immunofluorescence staining, immunoblot analysis, and gene analysis of cultured amniocytes obtained from a fetus at 16 weeks' gestational age. $\beta$-Oxidation activity, measured by $\left[1-{ }^{14} \mathrm{C}\right]$ lignoceric acid oxidation, was markedly decreased compared with the controls. Large peroxisomes were readily identified by immunofluorescence staining with anti-human catalase, as was found in the reported patients. Immunoreactive D-BP material was absent on immunoblot analysis and immunofluorescence staining with anti-human D-BP. Reverse transcriptase polymerase chain reaction (RT-PCR) analysis revealed the presence of the same 237-bp deletion in the cDNA as that detected in a sibling (the proband). The autopsied fetus showed the characteristic facial appearance and D-BP was deficient on immunoblot and immunohistopathological studies of the fetal tissues. No neuronal migration disorder was identified. This seems to be the first prenatal diagnosis of D-BP deficiency.
\end{abstract}

Y. Suzuki $(\bowtie) \cdot$ Z. Zhang $\cdot$ N. Shimozawa $\cdot$ N. Kondo

Department of Pediatrics, Gifu University School of Medicine,

Tsukasa-machi 40, Gifu 500-8705, Japan

Tel. +81-58-265-1241; Fax +81-58-265-9011

e-mail: ysuz@cc.gifu-u.ac.jp

M. Muro $\cdot$ H. Shono

Department of Obstetrics and Gynecology, Saga Medical College, Saga, Japan

S. Toda $\cdot$ S. Miyahara

Department of Pathology, Saga Medical College, Saga, Japan

T. Hashimoto

Department of Biochemistry, Shinshu University School of Medicine, Matsumoto, Japan

N. Usuda

Department of Anatomy, Shinshu University School of Medicine,

Matsumoto, Japan

M. Ito $\cdot$ S. Takashima

Department of Mental Retardation and Birth Defect Research,

National Center of Neurology and Psychiatry, Tokyo, Japan
Key words Peroxisomes - D-3-Hydroxyacyl-CoA dehydratase/D-3-hydroxyacyl-CoA dehydrogenase bifunctional protein deficiency $\cdot$ Prenatal diagnosis

\section{Introduction}

Isolated deficiencies of peroxisomal $\beta$-oxidation enzymes acyl-coenzyme A (CoA) oxidase (Poll-The et al. 1988, Suzuki et al. 1994a, 1996), 3-ketoacyl-CoA thiolase (Schram et al. 1987), enoyl-CoA hydratase/3-hydroxyacyl-CoA dehydrogenase bifunctional protein (L-BP) (Watkins et al. 1989), and D-3-hydroxyacyl-CoA dehydratase/D-3hydroxyacyl-CoA dehydrogenase bifunctional protein (DBP) (Suzuki et al. 1997), are characterized by the manifestation of severe psychomotor retardation and the accumulation of very-long-chain fatty acids (VLCFAs). Only VLCFAs accumulate in patients with acyl-CoA oxidase deficiency (Poll-The et al. 1988), whereas both VLCFAs and bile acid intermediates accumulate in patients with L-BP and D-BP deficiency (Watkins et al. 1989, Une et al. 1997).

D-BP converts enoyl-CoAs to 3-ketoacyl-CoAs via D-3hydroxyacyl-CoAs in peroxisomes (Jiang et al. 1996a, 1996b). Peroxisomal $\beta$-oxidation in human skin fibroblasts proceeds mainly by D-BP, but not by L-BP, as the content and activity of L-BP are very low in fibroblasts compared with that of D-BP (Jiang et al. 1997a). Bile acid precursors and 2-methyl-branched fatty acids are also catalyzed by D-BP (Jiang et al. 1997a).

Recently, we reported the first two patients with D-BP deficiency (Suzuki et al. 1997) who were diagnosed as having L-BP deficiency by means of a complementation study using an established cell line with L-BP deficiency (Suzuki et al. 1994a, 1996). Enzyme activity and D-BP immunoreactive material were markedly reduced compared with the controls, and deletions in the cDNA were identified (Suzuki et al. 1997). We proposed that patients previously diagnosed as having L-BP deficiency should be reexamined for possible D-BP deficiency. 
Here we present the first experience of the prenatal diagnosis of D-BP deficiency. Peroxisomal $\beta$-oxidation activity in cultured amniocytes from a fetus at 16 weeks' gestational age was markedly decreased compared with the controls and D-BP was absent on immunoblot analysis and immunofluorescence staining of cultured amniocytes. The same 237-bp deletion as that in a sibling (the proband) was detected in the cDNA. Biochemical and immunohistochemical studies confirmed that the fetus was affected.

\section{Methods}

\section{Patients and fetuses}

The proband was the second female child of nonconsanguineous parents of Japanese origin. Soon after birth, she manifested profound hypotonia, psychomotor delay, intractable convulsions, craniofacial dysmorphism (large fontanelle, frontal bossing, low nasal bridge, and upward-slanting of palpebral fissures), funnel chest, talipes equinovarus, calcific stippling of the patella, and hepatomegaly. She died of pneumonia at 12 months of age (Nakada et al. 1993). Accumulation of VLCFAs in plasma, and low lignoceric acid oxidation activity and D-BP activity in fibroblasts, as well as deficient immunoreactive D-BP material, were revealed. Molecular analyses revealed the presence of a 237-bp deletion in the cDNA of D-BP (Suzuki et al. 1997).

The third and fourth children were prenatally diagnosed as healthy by determination of lignoceric acid oxidation activity, and the diagnosis was confirmed by VLCFA analysis after birth (Table 1). In this study we examined cultured amniocytes and autopsied fetal tissue specimens from the fifth child. Control specimens (fibroblasts, amniocytes, and autopsied tissues) were obtained with permission from patients with other disorders.

\section{Methods}

Amniocytes obtained at 16 weeks' gestational age were cultured in MEM (Nissui, Tokyo, Japan). For immunofluorescence staining, about $1 \times 10^{4}$ cells were seeded on a sterile cover slip in a $3.5-\mathrm{cm}$ dish. For lignoceric acid oxidation, two dishes, each containing $1 \times 10^{5}$ cells, were used

Table 1 Biochemical data

\begin{tabular}{lcl}
\hline & $\begin{array}{l}{\left[1-{ }^{14} \mathrm{C}\right] \text { Lignocerate }} \\
\text { oxidation in } \\
\text { amniocytes (pmol/mg } \\
\text { protein per h) }\end{array}$ & $\begin{array}{l}\mathrm{C} 24: 0 / \mathrm{C} 22: 0 \\
\text { fatty acids } \\
\text { in serum } \\
\text { sphingomyelin }\end{array}$ \\
\hline Proband (second child) & 25 (fibroblasts) & 1.11 \\
Third child & 235 & 0.62 \\
Fourth child & 174 & 0.86 \\
Present fetus (fifth child) & 22 & 1.70 \\
Control fetus & $200 \pm 33$ & $0.71 \pm 0.10$ \\
\hline
\end{tabular}

${ }^{\mathrm{a}}$ These compounds are very-long-chain fatty acids
(Suzuki et al. 1994b). Peroxisomal $\beta$-oxidation activity was assessed by measuring the degradation products of $\left[1-{ }^{14} \mathrm{C}\right]$ lignoceric acid (CEA; Gif-Sur-Yvette, France) added to the medium, according to the method of Suzuki et al. (1991) with slight modifications. Amniocytes were preincubated with fetal calf serum-free MEM. The fatty acid oxidation reaction was initiated by adding $4 \mathrm{nmol}$ of $\left[1-{ }^{14} \mathrm{C}\right]$ lignoceric acid. After the preparation was incubated at $37^{\circ} \mathrm{C}$ for $1 \mathrm{~h}$, the medium was chilled on ice, and the unreacted fatty acid was removed. Radioactive degradation products were counted in a spectrophotometer. Sodium dodecyl sulfate (SDS)-polyacrylamide gel electrophoresis (PAGE) and western blotting were carried out as described (Laemmli 1970, Towbin et al. 1979). Color development was done with alkaline phosphatase-conjugated goat anti-rabbit IgG antibody and an NBT/BCIP substrate kit (Promega, Madison, WI, USA). Immunofluorescence staining of peroxisomes was performed as described (Suzuki et al. 1990), using rabbit anti-human catalase or anti-human D-BP antibodies. Extraction of mRNA from amniocytes, reverse transcriptase (RT)-polymerase chain reaction (PCR), and agarose gel electrophoresis were done as described (Suzuki et al. 1997, Jiang et al. 1997b), with the primer set 5'-TGTCGTTGCAGGCCTTATTC-3' and 5'TAATAGTGTAGTGTGCCCTTC-3'. Autopsied tissues were either kept at $-80^{\circ} \mathrm{C}$ for biochemical studies or fixed with $10 \%$ formalin for pathology studies. Immunohistochemistry of formalin-fixed paraffin-embedded tissues was performed by the peroxidase-antiperoxidase method, using anti-human D-BP antibody (Imamura et al. 1995).

\section{Results}

Biochemical and molecular analyses of amniocytes

Cultured amniocytes from the third and fourth children showed normal lignoceric acid oxidation activity, whereas the present fetus (the fifth child) showed decreased activity (Table 1). On immunoblot analysis, the 77-kDa band of D$\mathrm{BP}$ was absent in amniocytes from the present fetus as was the case with the proband, while immunoreactive material was clearly detected in the control fibroblasts (Fig. 1). Several faint smaller bands detected in the proband, the fetus,

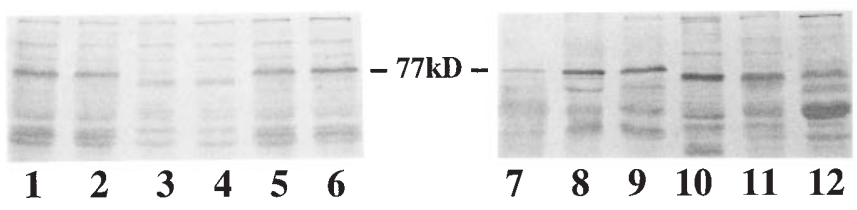

Fig. 1. Immunoblot analyses of peroxisomal D-3-hydroxyacylcoenzyme A (CoA) dehydratase/D-3-hydroxyacyl-CoA dehydrogenase bifunctional protein (D-BP). Lanes 1 and 2, Fibroblasts (control); lane 3, fibroblasts (proband); lane 4, amniocytes (present fetus); lanes 5 and 6, fibroblasts (control); lane 7, liver (control); lane 8, kidney (control); lane 9, brain (control); lane 10, liver (present fetus); lane 11, kidney (present fetus); lane 12, brain (present fetus). Twenty $\mu \mathrm{g}$ of protein was loaded 
Fig. 2. Indirect immunofluorescence staining. A Catalase (control fibroblasts); $\mathbf{B}$ catalase (present fetus, amniocytes); $\mathbf{C}$ D-BP (control fibroblasts); D D-BP (present fetus, amniocytes). Bar $=10 \mu \mathrm{m}$
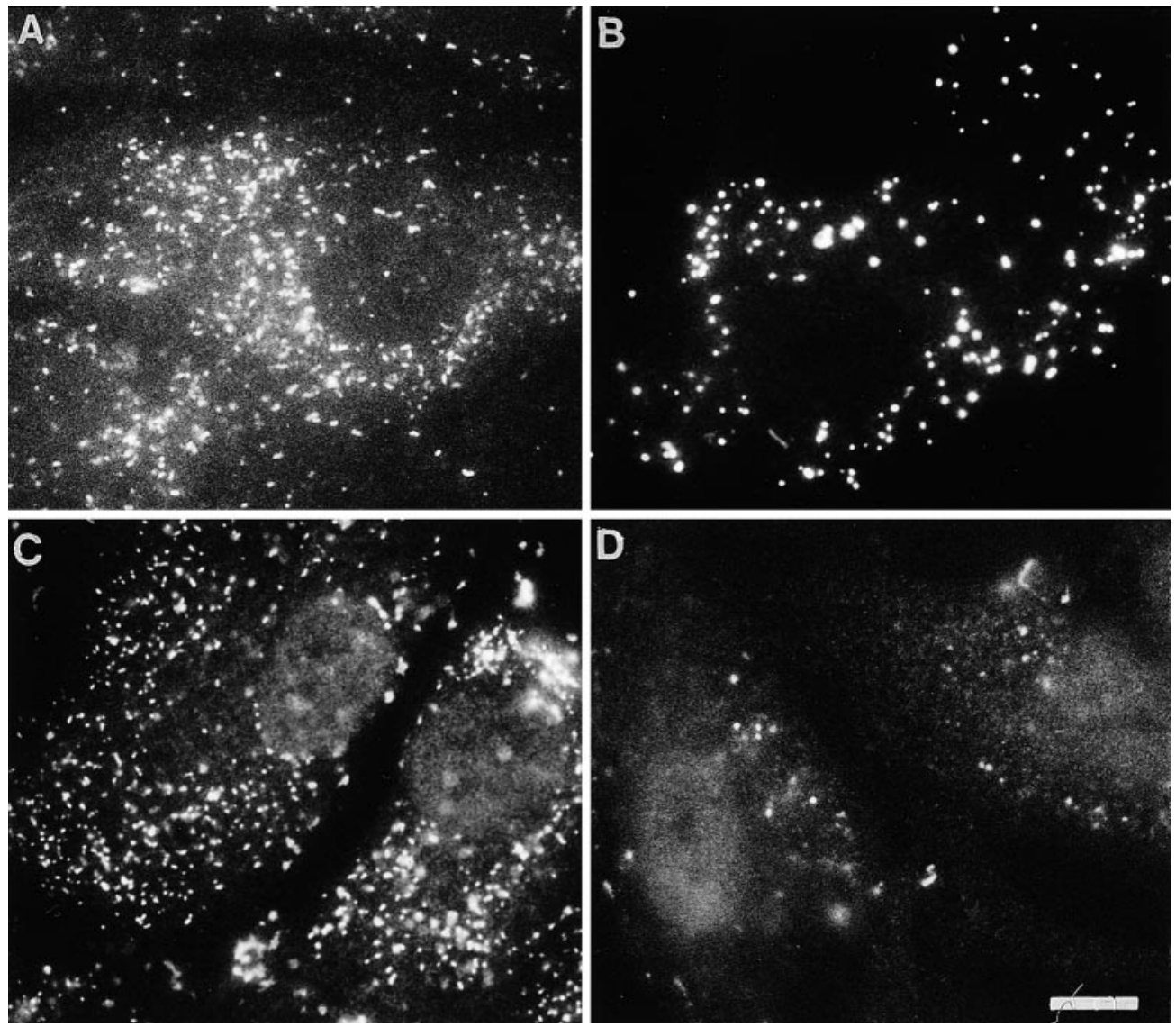

and the controls were considered to be nonspecific. Immunofluorescence staining with anti-human catalase antibody revealed that peroxisomes were larger and fewer in number in the present fetus than in the controls (Fig. 2B), as was the case with the proband (Suzuki et al. 1997), whereas practically no peroxisomes were detected in the present fetus when we used anti-human D-BP antibody (Fig. 2D). RTPCR using specific primers for $\mathrm{D}$-bifunctional protein revealed a 237-bp deletion in the cDNA of the present fetus (Fig. 3), which had also been identified in the proband (Suzuki et al. 1997). These results indicated that the present fetus was affected.

Immunohistochemical and biochemical analyses of fetal tissues

The parents were informed of the findings and they decided to terminate the pregnancy. They gave permission for an autopsy of the fetus. Fatty acid analysis of the cord blood revealed the accumulation of VLCFAs (Table 1). The fetus showed the characteristic facial appearance of D-BP deficiency, such as high forehead and low nasal bridge. Neuropathological examination revealed a cortical columnar cell arrangement with subcortical cells remaining in the cerebral hemisphere, and an immature cortex in the cerebellar hemisphere. However, there was no apparent neuronal migration disorder in the brain. Basal ganglia were normal. Liver and kidney tissues were normal in appear-

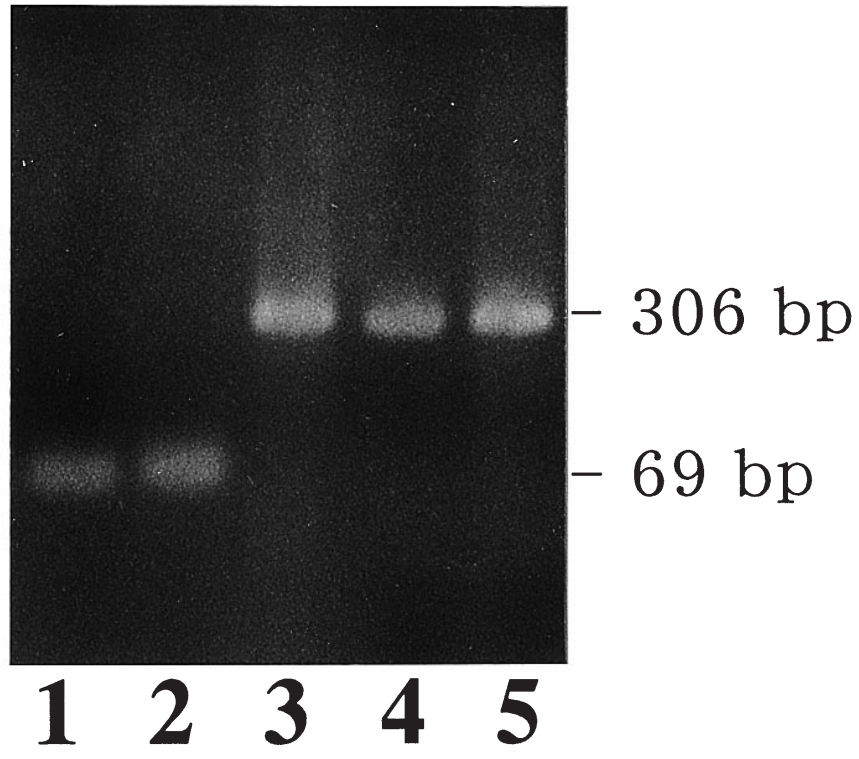

Fig. 3. Polymerase chain reaction amplification of D-BP cDNA and mutations in the proband and the present fetus. Lane 1, Present fetus; lane 2, proband; lanes 3,4 , and 5 , controls 

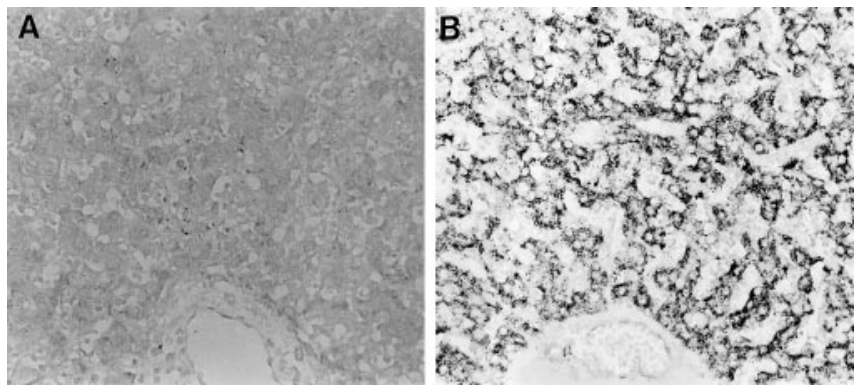

Fig. 4. Immunohistochemistry of D-BP in fetal liver tissues. A The present fetus; B control fetus

ance (data not shown). Immunoreactive D-BP material was absent in the liver, kidney, and brain tissues on immunoblot analysis. In the control fetus, D-BP was clearly identified. The absence of D-BP in the present fetus was also clarified by immunohistochemical staining of the liver (Fig. 4A), whereas D-BP was strongly expressed in the control fetal liver at 20 weeks of gestation (Fig. 4B).

\section{Discussion}

We have reported the presence of the novel peroxisomal $\beta$ oxidation enzyme, D-BP (Jiang et al. 1996a, 1996b, 1997a), and its congenital deficiency (Suzuki et al. 1997). L-BP deficiency was formerly considered to be the most frequent disorder among peroxisomal $\beta$-oxidation enzyme defects (Watkins et al. 1995). We proposed that patients previously diagnosed with L-BP deficiency should be re-examined for possible D-BP deficiency, and a recent study (van Grunsven et al. 1998) confirmed that the original case of possible L-BP deficiency reported by Watkins et al. (1989) was indeed D-BP deficiency. Based on these finding it seems that D-BP deficiency is the most frequent disorder among peroxisomal $\beta$-oxidation defects, and it is necessary to develop precise methods for its prenatal diagnosis.

Here we reported our experience of the first case of the prenatal diagnosis of D-BP deficiency and confirmed that several methods, including lignoceric acid oxidation assay, immunoblot, immunofluorescence staining, and RT-PCR were useful for the prenatal diagnosis of D-BP deficiency. These examinations, together, should provide us with precise results on a prenatal diagnosis of $\mathrm{D}-\mathrm{BP}$ deficiency. Compared with L-BP, D-BP is much more abundant in amniocytes, and it was easy to detect D-BP immunoreactive material in amniocytes by immunoblotting or immunofluorescence staining. Although several smaller bands other than D-BP were detected on immunoblot analyses, these bands were considered to be nonspecific, since practically no immunoreactivity was observed in the fetus on immunofluorescence staining and immunohistochemistry (Figs. 2, 4).

In the report of Kaufmann et al. (1996), an infant with bifunctional enzyme deficiency manifested neuronal migration disorder, showing heterotopic neurons, poly- microgyria, and simplified convolutions of the inferior olive, manifestations that are similar to those observed in Zellweger syndrome, a generalized peroxisome biogenesis disorder. Pathology examinations of the present fetus did not reveal the characteristic findings of neuronal migration disorders at 20 weeks of gestation. However, the presence of facial dysmorphism suggests that the pathological changes due to this enzyme deficiency had already progressed in mid-trimester, as is the case with Zellweger syndrome. In our immunohistochemical studies of the control fetus at 20 weeks of gestation, D-BP was strongly expressed in liver, kidney, and neurons (data not shown), suggesting that D-BP could play important roles in the development of fetal tissues, especially in the brain.

Acknowledgments Supported in part by a Grant-in-Aid for Scientific Research (10670718) from the Ministry of Education, Science, Sports and Culture of Japan, and by a Research Grant (8A-9) for Nervous and Mental Disorders from the Ministry of Health and Welfare of Japan.

\section{References}

Imamura A, Kamei A, Suzuki Y, Kondo N, Orii T, Takashima S (1995) Immunohistochemistry for a bifunctional protein in patients with peroxisomal disorders. Pediatr Neurol 12: 341-345

Jiang LL, Kobayashi A, Matsuura H, Fukushima H, Hashimoto T (1996a) Purification and properties of human D-3-hydroxyacylCoA dehydratase: Medium-chain enoyl-CoA hydratase is D-3hydroxyacyl-CoA dehydratase. J Biochem 120: 624-632

Jiang LL, Miyazawa S, Hashimoto T (1996b) Purification and properties of rat D-3-hydroxyacyl-CoA dehydratase: D-3-Hydroxyacyl-CoA dehydratase/D-3-hydroxyacyl-CoA dehydrogenase bifunctional protein. J Biochem 120: 633-641

Jiang LL, Kurosawa T, Sato M, Suzuki Y, Hashimoto T (1997a) Physiological role of D-3-hydroxyacyl-CoA dehydratase/D-3hydroxyacyl-CoA dehydrogenase bifunctional protein. J Biochem 121: 506-513

Jiang LL, Miyazawa S, Souri M, Hashimoto T (1997b) Structure of D-3-hydroxyacyl-CoA dehydratase/D-3-hydroxyacyl-CoA dehydrogenase bifunctional protein. J Biochem 121: 354-369

Kaufmann WE, Theda C, Naidu S, Watkins PA, Moser AB, Moser HW (1996) Neuronal migration abnormality in peroxisomal bifunctional enzyme defect. Ann Neurol 39: 268-271

Laemmli UK (1970) Cleavage of structural proteins during the assembly of the head of bacteriophage T4. Nature 227: 680-685

Nakada Y, Hyakuna N, Suzuki Y, Shimozawa N, Takaesu E, Ikema R, Hirayama K (1993) A case of pseudo-Zellweger syndrome with a possible bifunctional enzyme deficiency but detectable enzyme protein. Brain Dev 15: 453-456

Poll-The BT, Roels F, Ogier H, Scotto J, Vamecq J, Schutgens RBH, Wanders RJA, van Roermund CWT, van Wijland MJA, Schram AW, Tager JM, Saudubray JM (1988) A new peroxisomal disorder with enlarged peroxisomes and a specific deficiency of acyl-CoA oxidase (pseudo-neonatal adrenoleukodystrophy). Am J Hum Genet 42: 422-434

Schram AW, Goldfischer S, van Roermund CWT, Brouwer-Kelder EM, Collins J, Hashimoto T, Heymans HSA, van den Bosch H, Schutgens RBH, Tager JM, Wanders RJA (1987) Human peroxisomal 3-oxoacyl-coenzyme A thiolase deficiency. Proc Natl Acad Sci USA 84: 2494-2496

Suzuki Y, Yamaguchi S, Orii T, Tsuneoka M, Tashiro Y (1990) Nonspecific lipid transfer protein (sterol carrier protein-2) defective in patients with deficient peroxisomes. Cell Struct Funct 15: 301308

Suzuki Y, Shimozawa N, Yajima S, Yamaguchi S, Orii T, Hashimoto T (1991) Effects of sodium 2-[5-(4-chlorophenyl)pentyl]-oxirane-2carboxylate (POCA) on fatty acid oxidation in fibroblasts from patients with peroxisomal diseases. Biochem Pharmacol 41: 453-456 
Suzuki Y, Shimozawa N, Yajima S, Tomatsu S, Kondo N, Nakada Y, Akaboshi S, Iai M, Tanabe $\mathrm{Y}$, Hashimoto $\mathrm{T}$, Wanders RJA, Schutgens RBH, Moser HW, Orii T (1994a) Novel subtype of peroxisomal acyl-CoA oxidase deficiency and bifunctional enzyme deficiency with detectable enzyme protein: Identification by means of complementation analysis. Am J Hum Genet 54: 36-43

Suzuki Y, Shimozawa N, Kawabata I, Yajima S, Inoue K, Uchida Y, Izai K, Tomatsu S, Kondo N, Orii T (1994b) Prenatal diagnosis of peroxisomal disorders. Biochemical and immunocytochemical studies on peroxisomes in human amniocytes. Brain Dev 16: 27 31

Suzuki Y, Shimozawa N, Yajima S, Inoue K, Orii T, Kondo N (1996) Incidence of peroxisomal disorders in Japan. Jpn J Hum Genet 41: $167-175$

Suzuki Y, Jiang LL, Souri M, Miyazawa S, Fukuda S, Zhang Z, Une M, Shimozawa N, Kondo N, Orii T, Hashimoto T (1997) D-3hydroxyacyl-CoA dehydratase/D-3-hydroxyacyl-CoA dehydrogenase bifunctional protein deficiency: A newly identified peroxisomal disorder. Am J Hum Genet 61: 1153-1162
Towbin H, Staehelin T, Gordon J (1979) Electrophoretic transfer of protein from acrylamide gels to nitrocellulose sheets: Procedure and some applications. Proc Natl Acad Sci USA 76: 4350-4354

Une M, Konishi M, Suzuki Y, Akaboshi S, Yoshii M, Kuramoto T, Fujimura K (1997) Bile acid profiles in a peroxisomal D-3hydroxyacyl-CoA dehydratase/D-3-hydroxyacyl-CoA dehydrogenase bifunctional protein deficiency. J Biochem 122: 655-658

van Grunsven EG, van Berkel E, Mooijer PAW, Watkins PA, Moser HW, Suzuki Y, Jiang LL, Hashimoto T, Hoefler G, Adamski J, Wanders RJA (1999) Peroxisomal bifunctional protein deficiency revisited: Resolution of its true enzymatic and molecular basis. Am J Hum Genet (in press)

Watkins PA, Chen WW, Harris CJ, Hoefler G, Hoefler S, Blake DC Jr, Balfe A, Kelley RI, Moser AB, Beard ME, Moser HW (1989) Peroxisomal bifunctional enzyme deficiency. J Clin Invest 83: 771-777

Watkins PA, McGuinness MC, Raymond GV, Hicks BA, Sisk JM, Moser AB, Moser HW (1995) Distinction between peroxisomal bifunctional enzyme and acyl-CoA oxidase deficiencies. Ann Neurol 38: $472-477$ 